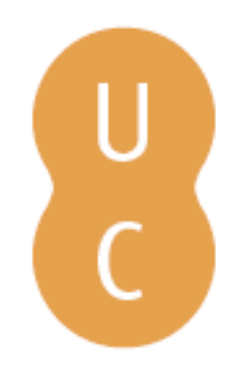

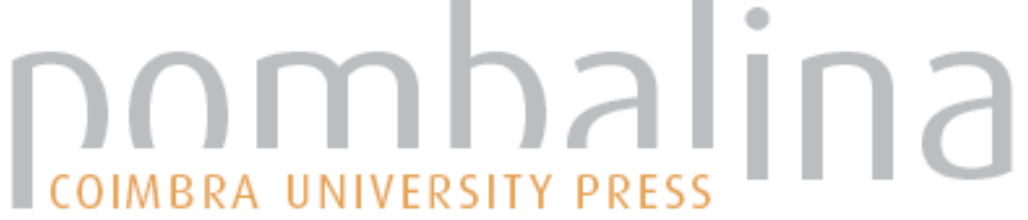

\section{A avaliação do dano corporal em crianças e idosos}

Autor(es): $\quad$ Borobia, César; Alías, Pilar; Pascual, Gloria

Publicado por: Imprensa da Universidade de Coimbra

URL

persistente: URI:http://hdl.handle.net/10316.2/32131

DOI: $\quad$ DOI:http://dx.doi.org/10.14195/978-989-26-0400-8

Accessed : $\quad$ 26-Apr-2023 16:27:35

A navegação consulta e descarregamento dos títulos inseridos nas Bibliotecas Digitais UC Digitalis, UC Pombalina e UC Impactum, pressupõem a aceitação plena e sem reservas dos Termos e Condições de Uso destas Bibliotecas Digitais, disponíveis em https://digitalis.uc.pt/pt-pt/termos.

Conforme exposto nos referidos Termos e Condições de Uso, o descarregamento de títulos de acesso restrito requer uma licença válida de autorização devendo o utilizador aceder ao(s) documento(s) a partir de um endereço de IP da instituição detentora da supramencionada licença.

Ao utilizador é apenas permitido o descarregamento para uso pessoal, pelo que o emprego do(s) título(s) descarregado(s) para outro fim, designadamente comercial, carece de autorização do respetivo autor ou editor da obra.

Na medida em que todas as obras da UC Digitalis se encontram protegidas pelo Código do Direito de Autor e Direitos Conexos e demais legislação aplicável, toda a cópia, parcial ou total, deste documento, nos casos em que é legalmente admitida, deverá conter ou fazer-se acompanhar por este aviso.

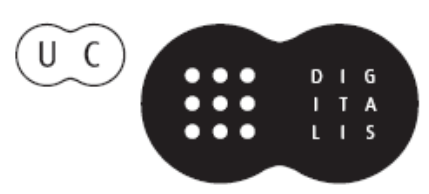




\section{Aspectos práticos da avaliação do dano corporal em Direito Civil}

Coordenação

Duarte Nuno Vieira

José Alvarez Quintero

Biblioteca Seguros 
(Página deixada propositadamente em branco) 


\title{
VIII - A Avaliação do Dano Corporal em Crianças e Idosos
}

\author{
César Borobia \\ Pilar Alías \\ Gloria Pascual
}

\section{AVALIAÇÃO DO DANO CORPORAL \\ NA INFÂNCIA}

\section{Gloria Pascual}

\section{César Borobia}

As sequelas que podem aparecer nas crianças podem ser tão variadas e graves como as dos adultos. Em geral, as crianças possuem uma adaptação e uma plasticidade que permitem, por um lado, que possam adaptar-se melhor que os adultos a situações de incapacidade, de modo que a sequela de um adulto de idade média (quarenta anos) que pode supor um deficit funcional para o resto da sua vida, numa criança de pouca idade vai permitir-Ihe adaptar-se e continuar com a sua vida normal. Por outro lado, uma sequela que para um adulto apenas the pode implicar o adiantar de um processo degenerativo iniludivel, para uma criança pode implicar uma limitação importante para a sua vida de relação com outras crianças. Portanto, é conveniente estudar as sequelas das crianças, não como as de um adulto em "tamanho pequeno", mas como pessoas com uma esperança de vida longa e com fortes possibilidades profissionais e sociais futuras.

As possibilidades de temas patológicos nos quais se deveria estudar as sequelas de uma criança ultrapassam muito os conteúdos deste capítulo. Por esse motivo, só se estudarão os seguintes temas:

- Lesões traumatológicas

- Lesões nos dentes

- Prejuizo estético

\section{LESÕES TRAUMATOLÓGICAS}

PARTICULARIDADES PEDIÁTRICAS NOS

\section{TRAUMATISMOS ÓSSEOS}

A peculiaridade dos ossos e articulações nas crianças é, sem dúvida, a existência das cartilagens 
de crescimento. Isto é especialmente evidente nos ossos compridos e tubulares das extremidades.

O traumatismo parcial ou total de uma cartilagem de crescimento implica uma assimetria de crescimento da extremidade óssea afectada e uma alteração da morfologia definitiva do osso afecto.

Em geral, a patologia traumatológica da infância tem um bom prognóstico.

A consolidação óssea é frequentemente rápi-da e com riscos mínimos de atraso na consolidação ou na aparição de pseudoartroses. Do mesmo modo, a remodelação óssea permite, na maioria dos casos, corrigir os defeitos de redução.

As possiveis sequelas que possam aparecer com o tempo após a cura ou a consolidação das lesões, podem avaliar-se dois ou três anos após o traumatismo inicial e sem necessidade de esperar pelo final do processo. No entanto, em caso de dúvida sobre o aparecimento de uma sequela, pode-se esperar pelo final do crescimento, sobretudo se a criança tiver uma idade próxima a esse momento. Pelo contrário, se a criança for de pouca idade não se pode pensar que é necessário esperar dez ou quinze anos para conhecer o alcance definitivo das sequelas.

A capacidade de remodelação óssea nas fracturas é muito maior na infância. Esta capacidade de remodelação do tecido ósseo em crescimento diminui com a idade e com a maturação do esqueleto. A remodelação óssea depende da conjunção dos fenómenos distintos e associados: por um lado, a remodelação pelo crescimento assimétrico da placa de crescimento e, por outro lado, pela remodelação da fractura in situ que corresponde a um efeito de reabsorção osteoclástica associada à oposição de ossos laminares.

\section{LESÕES TRAUMATOLÓGICAS HABITUAIS}

Existem múltiplas maneiras de classificar e estudar as lesões ortopédicas em geral e na criança em particular. Para este livro, preferimos tomar como base a existência de fracturas de acordo com a região anatómica. Deste modo, estudar-se-ão em primeiro lugar as dos ossos compridos e, posteriormente, as da coluna vertebral.

\section{FRACTURAS DE OSSOS COMPRIDOS}

\section{a) Fracturas diafisárias}

A rapidez relativa da consolidação e as características peculiares da remodelação óssea durante o crescimento, justificam uma atitude terapêutica menos agressiva do que se se tratar de um adulto e, portanto, a decisão cirúrgica é adoptada com menos frequência.

Os tipos de fracturas mais frequentes são as seguintes:

- Incurvação. Ocorre perante a compressão de um osso comprido. Os ossos mais frequentemente afectados são o cúbito e o perónio. A redução ortopédica é frequentemente difícil, apesar de ser o tratamento ideal em menores de doze anos.

- Fracturas incompletas. As crianças têm os ossos tão flexíveis que a maior parte das vezes sofrem fracturas chamadas incompletas. Correspondem à tradução mecânica da solidez do periósteo. São fracturas por flexão; os ossos dobram-se e fracturam-se apenas por um lado ficando a cortical e o periósteo intactos no lado oposto da fractura. Se não for imobilizado de forma eficaz, podem dar lugar a deslocações secundárias.

- Fracturas diafisárias. A incurvação plástica diafisária é uma fractura típica da infância que afecta principalmente os ossos com cortical fina, como são o rádio, o cúbito ou o perónio. 
Tendo em conta as peculiaridades da criança e a necessidade de esperar um tempo prudencial para assegurar a cura ou a consolidação das lesões, podem calcular-se estas últimas (na ausência de qualquer anomalia ortopédica evolutiva) num período de até três meses desde o traumatismo.

\section{b) Fracturas metafisárias}

A metáfise de um osso comprido tem um papel amortizador entre a epifise e a diáfise. As metáfises dos ossos compridos nas crianças apresentam um tecido ósseo muito esponjoso com uma corticalização ainda pouco marcada, facilitando aos ossos infantis a produção de fracturas metafisárias por compressão, chamadas também "protuberância", ao contrário das fracturas no adulto que são completas.

As fracturas mais frequentes são as seguintes:

- Fracturas supracondilianas do cotovelo. As fracturas do cotovelo são, por excelência, as fracturas mais comuns da infância. Cerca de 10\% das fracturas de crianças menores de dez anos localizam-se no cotovelo. Complicam-se com frequência por transtornos vasculonervosos (pela artéria umeral, o nervo mediano,...)

- Fracturas do colo do fémur. São muito pouco frequentes, mas de mau prognóstico porque, com uma certa frequência, produzem uma necrose avascular de cabeça e de colo femoral ou então o aparecimento de pseudoartrose.

- Fracturas do colo do rádio. São raras e, além disso, raramente requerem redução cirúrgica a céu aberto (com importante risco de necroses e de pseudoartrose).

O período de cura é variável, em geral é de algumas semanas, no entanto e, em função do tratamento, pode-se esperar até aos cinco meses.

\section{c) Fracturas epifisárias}

Estas fracturas afectam a cartilagem de crescimento, por isso, são as mais temidas. Têm a sua maior frequência na adolescência. Qualquer traumatismo da placa do crescimento é susceptível de provocar alterações de crescimento mais ou menos graves.

Em 1963, Salter e Harris introduziram uma classificação das lesões da zona epifisária-metafisária, dividindo-as em 5 tipos, dependendo da sua localização e do prognóstico, sendo esta a classificação mais amplamente utilizada actualmente.

- As fracturas tipo I de Salter estendem-se por toda a placa de crescimento, pelo que o principal risco de uma fractura nesta zona é o de produzir deformações ou alteração do crescimento normal da extremidade. Constituem 6-18\% de todas as fracturas de ossos compridos em crianças. Destas, $75 \%$ ocorre entre os 10 e os 16 anos. As localizações mais frequentes são o pulso e o tornozelo, sendo a localização óssea mais frequente a do rádio distal. Em aproximadamente $30 \%$ dos casos pode ficar como sequela um certo grau de encurtamento ou angulação, que no entanto só em $2 \%$ dos casos chega a ser clinicamente significativo com alteração funcional.

- As fracturas tipo II de Salter são as mais frequentes. Estas fracturas abarcam toda a placa de crescimento com uma extensão dentro da metáfise do lado de compressão da fractura. Pelo menos metade destas fracturas afecta a extremidade distal do rádio. Geralmente a redução é simples e pode resultar num encurtamento mínimo na maioria dos casos, excepto no joelho e tornozelo.

- As fracturas tipo III de Salter afectam toda a placa de crescimento e estendem-se dentro da articulação adjacente. Representa 8\% das lesões. Normalmente a deslocação é mínima e ocorre com maior frequência na região distal da tíbia e do fémur distal. o prognóstico é favorável, sendo raras as deformações. 
- As fracturas tipo IV de Salter são secundárias a uma força por compressão que cruza toda a zona de crescimento, comprometendo a metáfise, a fisis e a epifise. Estendem-se, portanto, desde a metáfise através da placa de crescimento até à articulação adjacente. Corresponde a $10-12 \%$ das lesões da zona de crescimento e as localizações mais comuns são o côndilo lateral do úmero e a tíbia distal. Esta lesão requer normalmente uma redução aberta para reduzir os fragmentos a uma posição anatómica. Como sequela pode-se encontrar um encurtamento da extremidade ou uma angulação, mais frequente no joelho e no tornozelo.

- As fracturas tipo V de Salter são as menos frequentes (constituem apenas 1\%) e são secundárias a uma força grave de compressão, que provoca um esmagamento da cartilagem de crescimento, comprometendo a produção vascular e lesionando as células germinais desta zona. Acontece com mais frequência no joelho, onde pode comprometer tanto a tíbia proximal como o fémur distal. Radiologicamente o diagnóstico pode ser difícil e as soluções consistem fundamentalmente numa diminuição na amplitude da fisis. Em controlos tardios pode ser evidente um encurtamento do osso ou uma angulação devido à detenção do crescimento da fisis na área afectada, estabelecendo-se o diagnóstico quando já se tiver instaurado a sequela.

Dentro das fracturas epifisárias deve-se prestar especial atenção às fracturas do côndilo externo do cotovelo. São fracturas relativamente frequentes e a sua importância radica no facto de se encontrarem por vezes problemas no diagnóstico, dependendo do estado de ossificação do núcleo epifisário do côndilo externo na criança. O seu tratamento é sempre cirúrgico, tendo como objectivo uma correcta redução anatómica e tentar evitar as complicações mais frequentes como são a pseudoartrose e o desvio axial.

Pode considerar-se como de bom prognóstico as fracturas tipo I e II de Salter, sendo mais graves quanto mais jovem for a criança, uma vez que as complicações consistentes na deteç̧ão do crescimento produzirão uma deformação maior.

As fracturas epifisárias necessitam de uma vigilância clínica e radiológica prolongada, na procura de uma alteração no crescimento (dismetria, alterações do eixo,...). Não é conveniente estabelecer um período orientativo de cura ou estabilização uma vez que vai depender de vários factores (idade da criança, tipo de lesão da cartilagem, tratamento efectuado,...). O recomendável é estabelecer um prognóstico em função da lesão da cartilagem e aplicar as tabelas de crescimento da cartilagem afectada para calcular a possivel dismetria.

\section{FRACTURAS DA COLUNA VERTEBRAL}

Na infância, este tipo de fracturas são raras, devido principalmente à grande elasticidade do esqueleto axial. Observam-se com mais frequência na adolescência e principalmente nos acidentes desportivos.

Um dos problemas graves destes traumatismos é a produção de lesões medulares sem evidência radiológica de lesão, pois pode não haver lesões ósseas radiológicas associadas. Complica ainda mais a situação o facto destas lesões coincidirem frequentemente com politraumatismos, e portanto, com outras lesões mais evidentes, pelo que devemos estar alerta.

A afectação da cartilagem de crescimento dos corpos vertebrais traduz-se frequentemente na aparição de uma escoliose ou de cifose. 0 tratamento, na maioria dos casos, é ortopédico e deve ser vigiado até ao final do crescimento. 0 tratamento cirúrgico é raro. 
O prognóstico destas fracturas é duplo:

- Imediato e derivado das lesões neurológicas ou de instabilidade vertebral.

- A longo prazo, em conjunto com a aparição de deformações frontais ou sagitais por assimetria do crescimento pós-traumático ou pós-cirúrgico.

0 processo de cura ou de consolidação é variável e difícil de estudar. Naquelas fracturas em que o crescimento não se afecta, este período pode estimar-se em menos de dez semanas. Naquelas em que as cartilagens de crescimento sejam afectadas ou se suspeite da existência futura de alterações das curvas da coluna vertebral, podem dar lugar a ter que esperar até ao final do crescimento.

\section{TRATAMENTO}

O objectivo do tratamento nas fracturas na infância é ajudar a uma consolidação precoce da fractura, evitando as deslocações dos fragmentos e as complicações mais frequentes, como são as alterações do crescimento com as consequentes dismetrias e desvios axiais.

0 tratamento mais frequente é, sem dúvida, o ortopédico. É necessário ter presente que o tempo de redução da fractura tem que ser o mais breve possivel, preferencialmente antes de 48 horas, para evitar a organização do hematoma.

A imobilização deve manter a redução da fractura in situ durante a fase de consolidação da mesma. 0 gesso é o método mais utilizado, sendo a sua duração variável em função do tipo e localização da fractura, apesar de, em geral, este período ser mais curto para as imobilizações de membros superiores do que para as dos inferiores assim como quanto mais jovem for a criança.

Um dos inconvenientes do tratamento ortopédico é a duração do mesmo e, portanto, a influência deste na vida escolar da criança, tal como: dificuldades de deslocação, para os jogos ou para a aprendizagem da escrita, etc.

Recorre-se ao tratamento cirúrgico com muito menor frequência e, em geral, nos casos de fracturas com grandes deslocações, dificuldades de tratamento imobilizador em polifracturados,...

\section{SEQUELAS}

As sequelas mais importantes que convém estudar são as dismetrias, as necroses vasculares epifisárias e as artroses precoces.

\section{a) Dismetrias}

Podem dever-se à lesão da cartilagem de crescimento de forma total ou parcial o que dá lugar a deformações angulares ou encurtamentos do membro afecto, tendo em conta a repercussão funcional destes, especialmente se afectam os membros inferiores.

Também pode produzir dismetria ou sobreposição óssea.

Na maior parte dos casos corrige-se espontaneamente durante o crescimento, sobretudo em crianças pequenas. Pode produzir-se também uma dismetria por excesso de crescimento do membro fracturado, provocado por uma hiperactividade da cartilagem de crescimento. Fisiologicamente é tolerável uma dismetria de até $1.5 \mathrm{~cm}$. A alteração de longitude pode considerar-se como definitiva decorridos dois anos após o acidente. Só as dismetrias de mais de $2 \mathrm{~cm}$ devem ser seguidas até ao final do crescimento.

Os calos viciosos corrigem-se melhor quanto mais jovem é a criança. 0 tempo de remodelação óssea pode requerer entre 2 e 5 anos. Um exemplo observa-se nas fracturas da metáfise tíbial superior da criança pequena que vão dar lugar a um joelho valgo característico.

\section{b) Necroses vasculares epifisárias}

Produzem-se por lesão dos vasos epifisários, 
afectando com mais frequência o rádio.

\section{c) Artroses precoces}

São uma complicação relativamente frequente das fracturas epifisárias, principalmente dos tipos III e IV de Salter.

\section{LESÕES ODONTOESTOMATÓLOGICAS}

Entre os seis e os doze anos, a idade escolar, encontra-se o grupo que com mais frequência sofre de lesões dentais da infância, devido à prática de jogos e desportos violentos.

As peças dentárias mais frequentemente afectadas são os incisivos, sobretudo os superiores.

Devido às características peculiares dos gérmenes dentários e do osso na infância, nas lesões dentárias devem ter-se em conta distintos factores. Nas lesões infantis entre um e três anos são muito frequentes os traumatismos em incisivos temporais e, em concreto, a perda do dente, luxações, as subluxações ou as intrusões.

A perda do dente não condiciona nenhuma sequela, apenas se detecta um aumento no tempo de erupção do dente definitivo.

Nas subluxações, devem vigiar-se especialmente as alterações dos gérmenes dentários mediante estudos radiológicos.

Quando a idade da criança for maior e o dano se produzir sobre as peças dentárias definitivas, as sequelas são mais importantes.

No caso de luxações deve tentar-se a sua reimplantação e ferulização. Complica-se frequentemente com a reabsorção radicular, que dá lugar à perda da peça.

Em geral, não se colocam nas crianças próteses fixas até aos 16 ou 18 anos, para evitar a afectação das peças adjacentes.

Em relação às fracturas que afectam os ossos maxilares deve-se destacar a possivel detecção do crescimento do osso mandibular, se afectar um núcleo de ossificação. Se a fractura se produzir antes dos doze anos, é necessário contemplar a possibilidade de afectação dos gérmenes dentários adjacentes, com a consequente perda das ditas peças dentárias.

Em qualquer caso deve-se esperar o final do crescimento ósseo da criança para avaliar correctamente as sequelas.

\section{PREJUIZZO ESTÉTICO}

É preciso ter em conta, para o estudo da avaliação do dano corporal a partir de um ponto de vista estético na infância, várias questões, como: a povoação a que pertence e as suas peculiaridades, a tipologia das lesões e a possivel evolução das mesmas.

As alterações estéticas na infância têm diferentes implicações conforme o lesionado seja uma criança pequena ou um adolescente.

Nas crianças pequenas a alteração estética não é vivida tanto por eles como pelo seu ambiente. Em geral, a preocupação é familiar, sobretudo dos pais, no que diz respeito não só ao transtorno estético em si mesmo, mas também às suas implicações futuras nos campos social, escolar e afectivo, com um desejo sempre presente de ter a constância de ter feito todo o possivel para a melhor recuperação do estado anterior.

Nos jovens, a importância que se atribui ao prejuízo estético tem uma relação mais directa com o seu ambiente social que a sua própria visão do defeito.

Um problema acrescentado ao anterior, deriva da determinação do momento da cura. Em geral, os defeitos estéticos de tipo estático (sobretudo cicatrizes) tendem a melhorar em poucos anos. Não devem criar problemas salvo se forem demasiado chamativas. Evidentemente 
que não se incluem nestes casos as monstruosidades da cara derivadas de queimaduras, sobretudo as que obrigam a criança a utilizar máscaras ou semelhantes. Nos casos de alterações estéticas de tipo dinâmico (encurtamento, por exemplo) a situação é diferente, até ao extremo de que, em ocasiões (como as citadas em páginas anteriores) será necessário esperar pela finalização do crescimento.

\section{AVALIAÇÃO NO IDOSO \\ Pilar Alías \\ César Borobia}

\section{CONCEITO E DEFINIÇÃO}

Ao referir-se ao idoso deve-se diferenciar claramente dois conceitos que, apesar de poderem parecê-lo, não são sinónimos: o paciente idoso e o paciente geriátrico. 0 paciente idoso refere-se exclusivamente à idade, que pode situar-se nos 65 anos para os paises desenvolvidos e nos 60 para os países subdesenvolvidos. Por isso, no nosso meio, considera-se o idoso como aquela pessoa que ultrapassou os 65 anos de idade. Pode falar-se de um subgrupo à parte para os "muito idosos" ou "muito velhos", em referência àquelas pessoas que ultrapassaram os 80 ou os 85 anos de idade.

0 paciente geriátrico, pelo contrário, faz referência não só à idade, que muitas vezes é o menos importante, mas também a uma série de patologias com as suas limitações físicas e psíquicas que por sua vez têm problemas sociais acrescentados.

Os últimos dados do Instituto Nacional de Estatística de Espanha manifesta um aumento da esperança de vida na povoação em todos os países da União Europeia. Em concreto, a esperança de vida ao nascer em Portugal no ano 2005 é de 74,90 anos para os homens e 81,33 para as mulheres $^{1}$. Este incremento da esperança de vida leva consigo um envelhecimento da povoação. Por sua vez, os avanços médicos e científicos, tornam possivel que uma ampla percentagem da povoação com mais de 65 anos viva sozinha e de forma autónoma, sem necessidade de ajuda para as actividades da vida diária.

Estes avanços médicos em conjunto com as medidas de prevenção, cada vez mais importantes, conseguiram nos últimos 30 anos incrementar a esperança de vida em pessoas com mais de 65 anos.

Quadro 1. Esperança de vida aos 60, 75 e 80 anos por sexo desde 1950 até 2020.

\begin{tabular}{|l|r|rrrrrr|}
\hline & & 1950 & 1980 & 1990 & 2000 & 2010 & 2020 \\
\hline \multirow{3}{*}{ Homens } & 60 & 15,4 & 17,3 & 19 & 20,3 & 21,6 & 22,8 \\
& 75 & 7 & 8,3 & 9,4 & 10,1 & 10,8 & 11,6 \\
& 85 & 3,7 & 4,5 & 4,9 & 5,2 & 5,6 & 5,9 \\
Mulheres & 60 & 18,4 & 22,4 & 24,2 & 25,7 & 27,1 & 28,4 \\
& 75 & 8,4 & 10,7 & 12 & 13 & 14 & 14,9 \\
& 85 & 4,4 & 5,4 & 6 & 6,5 & 7,1 & 7,6 \\
\hline
\end{tabular}

1 INE. Notas de prensa, 29 de octubre de 2007. www.ine.es/prensa/prensa.htm. 


\section{EPIDEMIOLOGIA}

O processo de envelhecimento não tem porque ser em si mesmo patológico, se bem que é certo que determinadas doenças são muito mais frequentes no idoso do que noutras idades da vida, assim como a incidência de doenças crónicas aumenta à medida que a idade avança.

A patologia do idoso pode classificar-se em quatro grupos:

a) Doenças que são específicas da sua idade e muito raras ou inexistentes noutras idades, por exemplo: o cancro de próstata, a osteoporose...

b) Doenças com uma incidência e prevalência mais alta do que noutras idades, por exemplo: a diabetes, a insuficiência cardíaca, ... c) Doenças que podem aparecer em qualquer idade mas que no idoso têm conotações tanto diagnósticas como terapêuticas diferentes, por exemplo: as infecções respiratórias, os traumatismos, ...

d) Doenças concomitantes, ou seja, a pluripatologia que envolve vários órgãos e que é muito mais frequente no idoso do que em qualquer outra idade.

No quadro abaixo (Krusen, 1993) recolhem-se algumas das alterações biológicas que se produzem no idoso.

\begin{tabular}{|c|c|c|}
\hline Órgão & Alterações morfológicas & Alterações fisiológicas \\
\hline Encéfalo & $\begin{array}{l}\text { Atrofia cortical } \\
\text { Perda de células nervosas } \\
\text { Depósitos de lipofucsina } \\
\text { Líquido ligeiramente diminuído }\end{array}$ & $\begin{array}{l}\text { Tempo de reacção prolongado } \\
\text { Diminuição de memória (principal- } \\
\text { mente anterogradual) } \\
\text { Diminuição da cognição }\end{array}$ \\
\hline $\begin{array}{l}\text { Nervo } \\
\text { periférico }\end{array}$ & Diminuição da mielina & Diminuição da velocidade de condução \\
\hline Músculo & $\begin{array}{l}\text { Diminuição do tamanho das fibras } \\
\text { musculares } \\
\text { Gordura e colágeno intersticial } \\
\text { Depósito de lipofucsina }\end{array}$ & $\begin{array}{l}\text { Diminuição da força, resistência } \\
\text { e velocidade }\end{array}$ \\
\hline $\begin{array}{l}\text { Osso e } \\
\text { articulações }\end{array}$ & $\begin{array}{l}\text { Cifose } \\
\text { Degeneração discal } \\
\text { Artrose } \\
\text { Osteoporose }\end{array}$ & $\begin{array}{l}\text { Diminuição da altura corporal } \\
\text { Diminuição da amplitude do movimento }\end{array}$ \\
\hline Coração & $\begin{array}{l}\text { Hipertrofia miocárdica } \\
\text { Arteriosclerose coronária* } \\
\text { Rigidez valvular }\end{array}$ & $\begin{array}{l}\text { Diminuição do vol/min* } \\
\text { Diminuição do fluxo coronário }\end{array}$ \\
\hline
\end{tabular}




\begin{tabular}{|c|c|c|}
\hline Órgão & Alterações morfológicas & Alterações fisiológicas \\
\hline $\begin{array}{l}\text { Vasos } \\
\text { sanguíneos }\end{array}$ & Rigidez da parede & $\begin{array}{l}\text { Aumento das resistências periféricas } \\
\text { Hipertensão arterial* }\end{array}$ \\
\hline $\begin{array}{l}\text { Parede } \\
\text { torácica }\end{array}$ & $\begin{array}{l}\text { Deformação (cifose) } \\
\text { Calcificação da cartilagem }\end{array}$ & Diminuição da distensibilidade \\
\hline Pulmões & $\begin{array}{l}\text { Diminuição do número de alvéolos } \\
\text { Dilatação dos brônquios } \\
\text { Diminuição da elasticidade e do parên- } \\
\text { quima }\end{array}$ & $\begin{array}{l}\text { Diminuição da capacidade respiratória } \\
\text { Enfisema* }\end{array}$ \\
\hline Rim & $\begin{array}{l}\text { Atrofia glomerular } \\
\text { Diminuição da massa de células tubu- } \\
\text { lares renais }\end{array}$ & $\begin{array}{l}\text { Diminuição do índice de filtração glo- } \\
\text { merular } \\
\text { Diminuição da função tubular }\end{array}$ \\
\hline
\end{tabular}

* Consideram-se doenças.

Além das anteriores devem também contemplar:

- Os transtornos na visão, a redução do campo visual e da agudeza visual, opacificação do cristalino. Tudo isso produz uma deteriorização na capacidade de adaptação às mudanças de contraste e luminosidade.

- A diminuição da capacidade auditiva, assim como uma redução da capacidade de adaptação às próteses auditivas.

- Dificuldades em mastigar.

- Alterações esfinterianas, como a urgência miccional e a incontinência, principalmente.

- As alterações do equilíbrio e da marcha, produzidas pela perda da elasticidade da membrana estratocónica e as alterações do sistema vestibular periférico ou central.

- Os transtornos na esfera afectiva, tendência para a depressão,...

As alterações, tanto físicas como psíquicas, que ocorrem no idoso pressupõem que este seja uma pessoa mais vulnerável aos acidentes (de tráfico, domésticos, na via pública, desportivos,...). A melhoria na qualidade e na esperança de vida faz com que os acidentes desportivos e de tráfico sejam contemplados como frequentes.

\section{PATOLOGIA ACIDENTAL MAIS FREQUENTE NO IDOSO}

As alterações que se produzem no idoso, como consequência do envelhecimento, convertem-no numa pessoa com uma maior vulnerabilidade para sofrer quedas e, devido ao seu estado de fragilidade, a que as consequências destas sejam mais graves do que o seriam em idades mais jovens. O traumatismo pode dar lugar a destabilizar uma situação prévia na qual o idoso era capaz de manter uma autonomia para as actividades da vida diária.

As lesões sofridas ocasionadas por um traumatismo são a primeira causa de morte acidental nas pessoas com mais de 65 anos e a quinta 
causa de morte por qualquer causa dentro da povoação idosa.

A probabilidade de fracturas perante traumatismos leves ou de pouca intensidade é muito maior no idoso devido, entre outros factores, a um maior grau de osteoporose. As fracturas mais frequentes no idoso são as fracturas de anca, as fracturas de pescoço e as fracturas vertebrais. As fracturas vertebrais e do pulso são frequentes antes dos 70 anos e as fracturas da cabeça do fémur são mais comuns depois dessa idade.

0 risco de sofrer uma fractura de pescoço femoral aos 80 anos é cinco vezes maior que o risco de a sofrer aos 50 anos. As sequelas e limitações derivadas destas fracturas são muito mais importantes do que em idades jovens. A mortalidade por fractura de anca no idoso é elevada durante o primeiro ano, sendo máxima nos quatro primeiros meses e igualando-se no final desse período à da povoação geral. A morbidade também é elevada, fazendo com que alguns destes idosos passem a um estado de dependência. Este tipo de fracturas, ao contrário dos jovens, aparece no idoso perante traumatismos leves, e inclusivamente sem um traumatismo aparente, o que é favorecido pelo facto de ser um osso com uma resistência diminuída pela osteoporose.

Os factores de risco para sofrer uma fractura de pescoço femoral podem ser: factores intrínsecos e factores extrínsecos.

\begin{tabular}{|l|l|}
\hline FACTORES INTRÍNSECOS & FACTORES EXTRÍNSECOS \\
\hline Idade superior a 80 anos & Deslumbramento \\
Transtornos da marcha e do equilibrio & Irregularidades no terreno \\
Deficit cognitivos & Má iluminação \\
Transtornos na visão & Obstáculos em lugares de passagem \\
Tratamento com psicotrópicos & Outros \\
Hipotensão arterial & \\
Sedentarismo e amiotrofia & \\
Pluripatologia & \\
\hline
\end{tabular}

Nas fracturas de pulso a necessidade de tratamento cirúrgico e o tempo médio de hospitalização é maior e mais prolongado em pessoas com idades superiores a 60 anos. Além disso, certas complicações como a algodistrofia e o atraso na consolidação ocorrem aproximadamente em 30\% dos casos, número muito superior aos de outras idades. As limitações funcionais residuais assim como a dor são também mais frequentes.

Outra patologia que não se pode esquecer é o desenvolvimento de um quadro de confusão agudo ou delírio. É uma síndrome orgânica cerebral caracterizada por uma alteração da consciência, com alterações nas funções cognoscitivas que se desenvolve ao longo de um período breve de tempo. Produz-se uma alteração da consciência, da atenção, do pensamento, da percepção e da memória. É um quadro que, apesar de poder aparecer em qualquer idade, se dá com uma maior frequência entre a povoação idosa, atingindo $15 \%$ nos idosos internados no hospital e até $50 \%$ naqueles que se encontram integrados 
numa residência. São factores precipitantes deste quadro: as infecções, a toma de certos medicamentos (fármacos anticolinérgicos), as alterações metabólicas, as alterações endócrinas e a cirurgia prévia. No desenvolvimento deste quadro a fractura de anca joga um papel importante. O prognóstico vai depender da causa mas, em geral, o quadro limita-se a umas horas ou dias regressando de novo à sua situação basal.

Os transtornos do humor e a depressão implicam um capítulo muito importante dentro da patologia do idoso. Ocasionalmente será necessário fazer um diagnóstico diferencial com a demência e os quadros pseudo demenciais. A disfunção neuropsicológica produzida depois de um traumatismo pode ser a origem destes quadros.

\section{AVALIAÇÃO FUNCIONAL DO IDOSO}

A avaliação do idoso deve contemplar, não apenas as limitações funcionais que apresenta mas também, e com igual importância, os problemas mentais e os problemas sociais.

A avaliação geriátrica pode agrupar-se em quatro secções:
A) Avaliação geral
B) Avaliação funcional
C) Avaliação mental ou cognitiva
D) Avaliação social

\section{A) Avaliação geral}

Nesta primeira fase ter-se-á em conta, não apenas a patologia que é objecto da avaliação, mas também as possiveis patologias anteriores, o estado nutricional, os medicamentos que toma e o estudo da função renal. Seria o equivalente à primeira parte da história clínica do paciente.

\section{B) Avaliação funcional}

Posteriormente terá que estudar as limitações funcionais que apresenta para as actividades da vida diária quer sejam actividades básicas, instrumentais ou avançadas, assim como os transtornos da marcha e os deficits perceptivos que possam existir.

1. Avaliação das actividades básica da vida diária (comer, deslocar-se, lavar-se, controlo de esfíncteres). A perda destas funções produz-se de maneira ordenada e inversa àquela que se adquiriu na infância. Para isso dispõe-se de escalas validadas. Uma das mais utilizadas é o indice de Katz (Quadro 2). Em Espanha, usa-se com frequência a escala da Cruz Vermelha de incapacidade física e mental.

Quadro 2. Índice de Katz de independência nas actividades da vida diária
A. Independente na alimentação, continência, mobilidade, uso da sanita, vestir-se e tomar banho.
B. Independente para todas as funções anteriores excepto uma.
C. Independente para todas excepto tomar banho e outra função adicional.
D. Independente para todas excepto tomar banho, vestir-se e outra função adicional.
E. Independente para todas excepto tomar banho, vestir-se, usar a sanita e outra função adicional.
F. Independente para todas excepto tomar banho, vestir-se, usar a sanita, mobilidade e outra função adicional.
G. Dependente nas seis funções.
H. Dependente em, pelo menos, duas funções, mas não classificável como C, D, e F. 
Independente significa sem supervisão, direcção ou ajuda pessoal activa, com as excepções que se indicam mais abaixo. Baseiam-se no estado actual e não na capacidade de as executar. Considera-se que um paciente que se nega a realizar uma função não faz essa função, apesar de ser considerado capaz.

Tomar banho (com esponja, duche ou banheira):

Independente: necessita de ajuda para se lavar num só local (como as costas ou uma extremidade incapacitada) ou lava-se completamente sem ajuda.

Dependente: necessita de ajuda para se lavar em mais do que uma parte do corpo, para sair ou entrar na banheira, ou não se lava sozinho.

\section{Vestir-se:}

Independente: pega a roupa sozinho, veste-a, coloca acessórios e abrigos e usa fechos (exclui-se o acto de atar os sapatos).

Dependente: não se veste sozinho ou permanece vestido parcialmente.

Usar a sanita:

Independente: acede à sanita, entra e sai dela, limpa os órgãos excretores e arranja a roupa (pode usar ou não suportes mecânicos).

Dependente: usa penico ou urinol ou precisa de ajuda para aceder à sanita e utilizá-la.

\section{Mobilidade:}

Independente: entra e sai da cama e senta-se e levanta-se da cadeira sozinho (pode usar ou não suportes mecânicos).

Dependente: precisa de ajuda para utilizar a cama e/ou a cadeira; não realiza uma ou mais deslocações.

\section{Continência:}

Independente: controlo completo de miç̧ão e defecação.

Dependente: incontinência urinária ou fecal parcial ou total.

\section{Alimentação:}

Independente: leva a comida desde o prato ou seu equivalente até à boca (exclui-se cortar a carne e barrar a manteiga ou similar).

Dependente: precisa de ajuda para a acção de se alimentar, ou necessita de alimentação entérica ou parentérica.

0 resultado é informado mediante a letra adequada, por exemplo: Índice de Katz: C.

\section{Avaliação das actividades instrumentais} da vida diária. Trata-se de actividades mais complexas que pressupõem um maior grau de autonomia do idoso. Dentro destas actividades incluem-se: utilizar o telefone, ir às compras, preparar a comida, cuidar da casa, lavar a roupa, utilizar os meios de transporte, a responsabilidade sobre a medicação e a capacidade de utilizar dinheiro. Uma escala utilizada para isto é a escala de Lawton e Broy (Philadelphia Geriatric Center) que se descreve no Quadro 3. 


\section{Quadro 3. Escala de actividades instrumentais da vida diária}

A informação será obtida de um cuidador fidedigno. Pontua-se cada área conforme a descrição que melhor corresponde ao sujeito. Portanto, cada área pontua um máximo de $\mathbf{1}$ ponto e um mínimo de $\mathbf{0}$ pontos.

Capacidade para usar o telefone

Utiliza o telefone por iniciativa própria:

É capaz de marcar bem alguns números familiares:

1 ponto

É capaz de atender o telefone, mas não de marcar:

1 ponto

Não é capaz de usar o telefone:

1 ponto

0 pontos

Fazer compras

Realiza todas as compras necessárias independentemente:

1 ponto

Realiza independentemente pequenas compras:

0 pontos

Necessita ir acompanhado para fazer qualquer compra:

0 pontos

Totalmente incapaz de fazer compras:

0 pontos

Preparação da comida

Organiza, prepara e serve a comida por si só adequadamente:

1 ponto

Prepara adequadamente a comida se the proporcionarem os ingredientes:

0 pontos

Prepara, aquece e serve as comidas, mas não segue uma dieta adequada:

0 pontos

Necessita que the preparem e sirvam a comida:

0 pontos

Cuidado da casa

Mantém a casa sozinho ou com ajuda ocasional (para trabalhos pesados):

Realiza tarefas ligeiras, como lavar os pratos ou fazer as camas:

1 ponto

1 ponto

Realiza tarefas ligeiras, mas não pode manter um adequado nível de limpeza:

1 ponto

Necessita de ajuda em todas as tarefas da casa:

Não participa em nenhuma tarefa da casa:

1 ponto

0 pontos

Lavagem da roupa

Lava por si só toda a sua roupa:

Lava por si só pequenas peças:

1 ponto

1 ponto

Toda a lavagem de roupa deve ser realizada por terceiros:

0 pontos

Uso de meios de transporte

Viaja sozinho em transporte público ou conduz o seu próprio carro:

É capaz de apanhar um táxi, mas não usa outro meio de transporte:

1 ponto

1 ponto

Viaja em transporte público quando vai acompanhado por outra pessoa:

1 ponto

Só utiliza o táxi ou o automóvel com ajuda de terceiros:

0 pontos

Não viaja:

0 pontos

Responsabilidade relativamente à sua medicação

É capaz de tomar a sua medicação à hora e com a dose correcta:

1 ponto

Toma a sua medicação se a dose Ihe for previamente preparada:

0 pontos

Não é capaz de administrar a sua medicação:

0 pontos

Tratar dos seus assuntos económicos

Encarrega-se dos seus assuntos económicos por si mesmo:

1 ponto

Realiza as compras de cada dia, mas necessita de ajuda nas grandes

compras, bancos... :

1 ponto

0 pontos

Incapaz de gerir dinheiro:

Avaliação da pontuação:

Somam-se os pontos correspondentes a todas as áreas para obter um total. A máxima dependência estaria marcada pela obtenção de um total de $\mathbf{0}$ pontos, enquanto que uma soma de 8 pontos expressaria uma independência total. Esta escala é mais útil em mulheres, uma vez que muitos homens nunca realizaram algumas das actividades que se avaliam. 
144 VIII - A Avaliação do Dano Corporal em Crianças e Idosos

3. Avaliação das actividades da vida diária avançadas. Avaliam-se nesta secção as actividades lúdicas, profissionais, culturais...

\section{C) Avaliação cognitiva}

A integridade da função cognitiva é de suma importância para a manutenção da independência do idoso. Nela se integram funções intelectuais tais como recordar, perceber, orientar-se, ser capaz de expor e resolver problemas, ... Deve ser realizada com rigor, por pessoal experiente e descartando possiveis patologias subjacentes que foram a causa da perda da capacidade cognitiva. Existem questionários que podem ajudar a sua avaliação, sem que isso pressuponha que se descarte a realização de outras provas complementares e inclusive a intervenção de especialistas. Os questionários mais utilizados são o questionário de Pfeifer e o Mini-Mental Exam de Folstein (em Espanha a versão validada de Lobo) disposto no Quadro 4.

\section{D) Factores sociais}

Nesta seç̧ão ter-se-á em conta a vida social do idoso, a existência de cônjuge, amigos, relações familiares, tipo de casa e acesso aos serviços sociais e sanitários, necessidade de ajuda no domicílio, quer seja parcial, total.... 
Quadro 4. Mini exame cognoscitivo

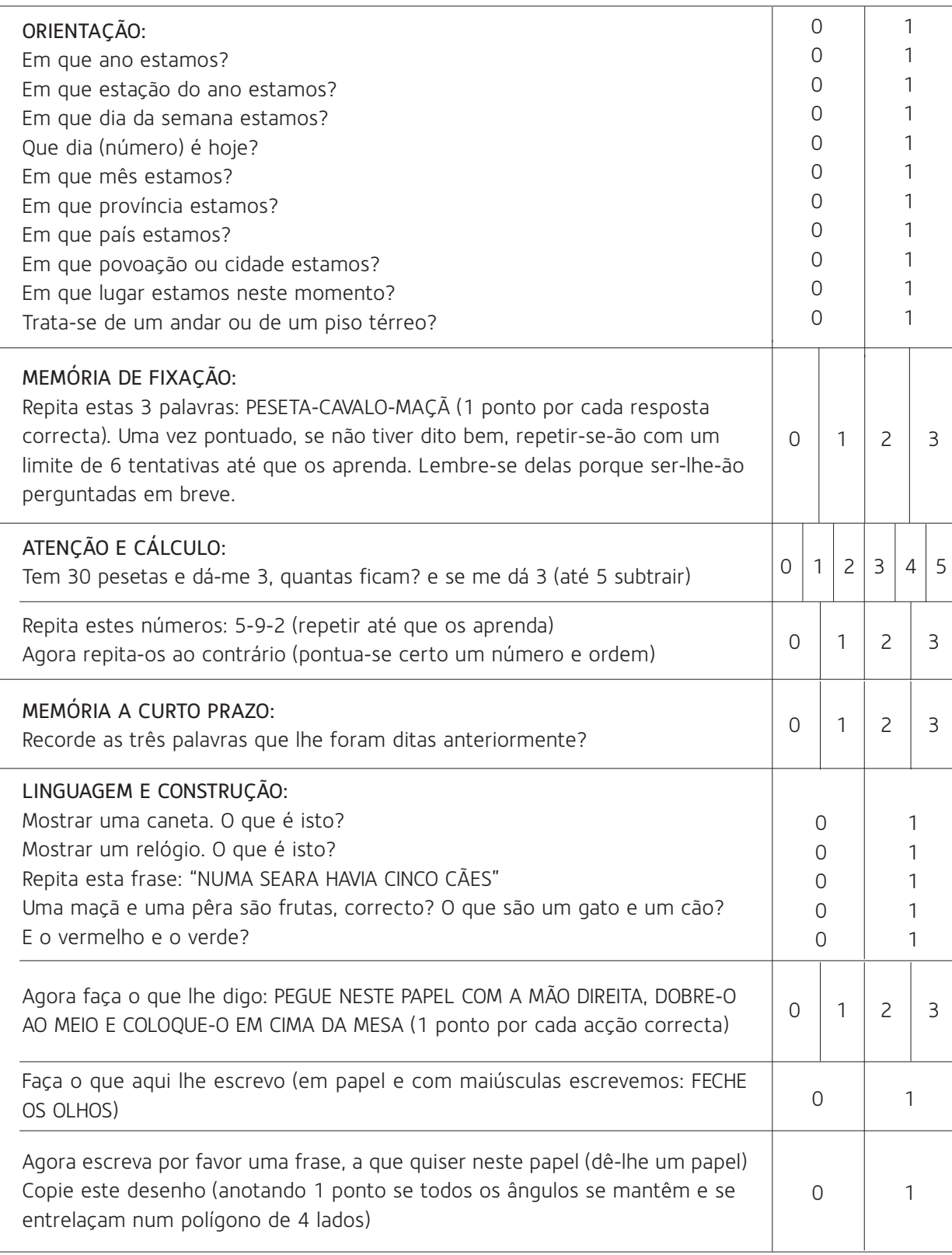




\section{BIBLIOGRAFIA}

BOROBIA FERNANDEZ, César - Valoración de daños personales. Informes periciales e casos prácticos. Madrid: La Ley-Actualidad, 1998.

BOROBIA FERNANDEZ, César - Valoración del dano corporal. Medicina de los seguros. Miembro superior. Elsevier-Masson, 2007. BOROBIA FERNANDEZ, César - Valoración del dano corporal. Medicina de los seguros. Miembro inferior. Elsevier-Masson, 2007. BOROBIA FERNANDEZ, César - Valoración del dano corporal. Medicina de los seguros. columna, pelvis e parrilla costal. Elsevier-Masson, 2008.

COLBEAU-JUSTIN, Ph. - La consolidation médico-légal chez l'enfant après traumatismo médullaire. Revue francaise du dommage corporel. J. B. Baillière éditeur. vol.29(2) (2003), p. 105-109.

DAUPLEIX, Ch. - La consolidation médico-légal dans les traumatismos odontostomatologiques de l'enfant. Revue francaise du dommage corporel. J. B. Baillière éditeur. vol.29(2) (2003), p. 121-137.

DESPLAT, P. - Consolidation médico-légale chez l'enfant et préjudice esthétique. Revue française du dommage corporel. J. B. Baillière éditeur. vol.29(2) (2003), p. 111-120.

GERVAIS, Ch. - La consolidation médico-légale chez l'enfant. Une notion délicate á appréhender. Revue francaise du dommage corporel. J. B. Baillière éditeur. vol.29(2) (2003), p. 77-83.

GÓMEZ DE MAEMBRILLERA, Gascó; GASCÓ ADRIEN, J.

www.sepeap.org/imagenes/secciones/Image/-USER-/Traumatologia-epidemiologia-fracturas(2). Pdf. Dezembro 2007.

GUET, J. L [et al.] - La réparation du dommage corporel en droit commun. Paris: Ed. Masson, 1980.

HERNANDÉZ CUETO, Claudio - Valoración del dano corporal. Guía práctica para la exploración y evaluación de lesionados. $2^{a}$ ed. Barcelona: Masson, 2001.

KRUSEN - Medicina Física e Rehabilitação. $4^{a}$ ed. Madrid: Panamericana, 1993.

LECHEVALLIER, J. - Les traumatismes da cheville de l'enfant. Revue francaise du dommage corporal. J. B. Baillière éditeur. vol.32(3) (2006), p. 181-193.

PEREA, B. - Metodología para la AVALIAÇÃO del DANO en odontoestomatología. www.cej.justicia.es/pdf/publicaciones/medicos-forenses/MEDI42.pdf. Dezembro 2007

RIBERA, J. M.; CRUZ A. J. - Geriatría en Atenção Primaria. $2^{\text {a }}$ ed. Barcelona: J. Uriach, 1997.

Revue Française du Dommage Corporel. J.B. Baillière éditeur. Tome 31, n. ${ }^{\circ} 3$ (2005).

Revue Française du Dommage Corporel. J.B. Baillière éditeur. Tome 32, n. ${ }^{\circ}$ (2006). 



\section{Biblioteca Seguros}

Publicação da Caixa Seguros

Co-edição Caixa Seguros e Imprensa da Universidade de Coimbra

\section{Título}

Aspectos práticos da avaliação do dano corporal em Direito Civil

\section{Coordenação}

Duarte Nuno Vieira e José Alvarez Quintero

\section{Tradução}

Sónia Almeida

Design

Liquid Design

Impressão

SerSilito-Empresa Gráfica, Lda.

ISBN 978-989-8074-31-7

Depósito Legal 279157/08

Julho 2008 

CAIXA SEGUROS, SGPS, S.A.

Grupo Caixa Geral de Depósitos 